\title{
Entrevista: Prof. Dr. Giovanni Guido Cerri
}

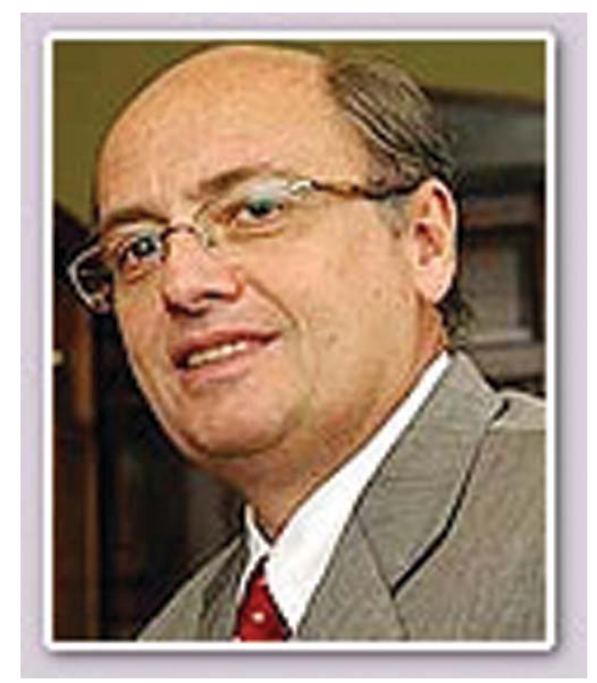

\section{R.M. O senhor terminou a graduação em 1976 na FMUSP. Mudou muito a graduação daquela época para hoje?}

Eu fiz o curso Experimental, que era uma proposta de ensino mais moderna, que saía do esquema convencional, de aulas teóricas no anfiteatro. Tinha muita aula-reunião em grupo. Essa nova concepção foi introduzida no curso Único, que saiu depois que acabou o curso Experimental. A partir daí, o curso de Medicina passou a ser um curso com aulas teóricas e, em particular na clínica, discussões de casos clínicos, com divisões em pequenos grupos. Então, eu passei por uma fase de transição do curso de Medicina, de uma concepção de curso tradicional, muito voltado a exposições teóricas com apenas uma parte prática no internato, para um curso que se assemelha mais aos moldes atuais. O ensino da FMUSP é muito cíclico. Como docente, eu participei da experiência dos blocos, onde todo o ensino da Gastroenterologia se dava em conjunto, com a patologia, a Radiologia. Era um modelo que funcionou muito bem, quando todas as disciplinas se uniam dentro de um bloco, da Gastroenterologia. As Moléstias Infecciosas foi um bloco que sobreviveu a isso, que até hoje é dessa forma. Eu vejo que as idéias vão e vem, mas o que faltava muito na nossa Faculdade era uma questão de infra-estrutura, que nós tentamos investir um pouco na última gestão, ou seja, em laboratórios de habilidades, espaços mais voltados para um ensino mais moderno. Na minha época eu vivi a experiência do curso Experimental, que foi uma experiência de um ensino inovador, e acho que foi uma experiência que deu certo. Quem estava à frente desse curso era o Eduardo Marcondes e Isaias Raw. O Isaias acabou saindo do país depois, por uns problemas da revolução e hoje ele está à frente do Instituto Butantã. Então era um grupo de professores que tinha pensado em uma proposta inovadora, e eu acho que a FMUSP tem que ter propostas inovadoras, tem que mostrar que o ensino também deve ser modificado ao longo do tempo, e que tem que ter experiências que mostrem resultados.

\section{R.M. O senhor acha importante fazer Iniciação Científica? O senhor fez na sua época?}

$\mathrm{Na}$ minha época o que acontecia era que os alunos que achavam que tinham uma vocação e gostavam de uma disciplina especificamente, geralmente procuravam o professor da disciplina e o acompanhavam, freqüentavam. Eu fiz isso em Cirurgia. Teve uma época em que eu pensava em fazer Cirurgia, e tinha me vinculado a um professor 
de Cirurgia e acompanhava-o dentro e fora da Escola, operando nos hospitais que ele ia. Então, a iniciação científica existia de um modo mais informal, ou seja, os alunos se vinculavam aos professores que eram abertos a essa idéia e passavam, então, a trabalhar em conjunto. Mas era uma iniciação científica muito voltada para a assistência, porque naquela época a Faculdade ainda sofria o esvaziamento das disciplinas básicas, da pesquisa. A Faculdade visava formar médicos especialistas. Depois, a iniciação científica, que também é interessante, passou a envolver as disciplinas, e a fazer com que os alunos pudessem se envolver em pesquisas clínicas, do serviço, e eventualmente em pesquisas laboratoriais. É uma forma do aluno estar mais próximo da estrutura da Faculdade, do laboratório, da assistência do dia-a-dia, de verem como realmente o paciente é atendido, que é diferente da experiência que ele tem ao longo dos seis anos, mais distante e superficial, e envolver-se em uma disciplina específica, que pode ou não vir a ser a especialidade escolhida. A iniciação científica é uma forma de complementar o curso de graduação. Acho que todo aluno deveria fazer, independente ou não de seguir a especialidade. E muito comum o aluno fazer a iniciação científica em uma determinada disciplina e depois escolher outra. Não tem importância, porque a vivência que se cria é muito positiva.

\section{R.M. E o que levou ao senhor escolher a Radio- logia, se o senhor queria a Cirurgia?}

Na minha época a Cirurgia era uma especialidade que atraía muito os alunos, era uma especialidade muito nobre, e a gente entra na Faculdade pensando em fazer uma determinada coisa. Mas, tirando raros casos, a decisão da especialidade se dá muito no internato, porque no internato você vai descobrindo o que é cada especialidade. Eu gostava muito de Psiquiatria e acho que seria a especialidade que eu teria escolhido. Mas vocês não conheceram o que era o Instituto de Psiquiatria aqui antigamente. Parecia uma prisão, era um lugar horroroso, com os pacientes trancados. A estrutura da Psiquiatria naquela época desmotivava as pessoas a seguirem a Psiquiatria. Acabei escolhendo a Radiologia porque identifiquei que era uma especialidade que ia crescer muito, uma especialidade do futuro. A nossa Radiologia aqui era muito rudimentar, mas, quem acompanhava, via que estava surgindo a Tomografia Computadorizada, o Ultra-Som, a Radiologia Intervencionista. No mundo, a Radiologia estava se movendo. Então eu escolhi muito pelo desafio de uma especialidade que estava em crescimento, em expansão, que envolvia muita modernidade. Eu vi na Radiologia a oportunidade de fazer alguma coisa diferente e muito promissora. E apesar da nossa Radiologia aqui ser muito primária, ser mal instalada, foi a especialidade que eu escolhi e acabei tendo a oportunidade de ajudar a fazer a Radiologia crescer aqui dentro. Vocês verão em breve, daqui a duas semanas, nós iremos inaugurar o novo Instituto de Radiologia, que é um serviço de Radiologia que não tem em nenhum hospital privado daqui de São Paulo, um serviço também montado por nós. Será uma Radiologia toda digital e será tudo montado nesse ano, as imagens chegarão ao centro cirúrgico, nas enfermarias por via digital, as imagens serão todas na tela, o filme vai ser suprimido, até a física é muito moderna. Esse ano nós estamos completando essa transformação de uma Radiologia realmente do século XXI.

\section{R.M. O que o senhor achou de fazer a especiali- zação fora do país e qual era a principal diferença de fazer fora e aqui?}

A Radiologia daqui, e do país, tinha uma estrutura que não tinha incorporado os avanços tecnológicos da especialidade, que, aliás, mesmo fora, ainda estavam sendo incorporados. Eu acompanhei no hospital onde eu trabalhei a instalação do primeiro tomógrafo de corpo inteiro, antes só faziam crânio. O primeiro tomógrafo de corpo inteiro foi uma grande inovação. E a Radiologia era uma coisa que estava em grande explosão fora do país, em particular nos Estados Unidos. Aqui ainda era futuro, não tinha nem projeto de incorporação dessas novas tecnologias. Então eu achei que para mim era fundamental que eu pudesse ver o amanhã da Radiologia, e é por isso que eu fui para o exterior ainda durante minha residência. $\mathrm{Na}$ época a residência da Radiologia era curta, de dois anos. A maior parte das residências eram de dois anos. Na metade do meu curso de residência eu fui para o exterior, acabei minha residência lá e tive uma idéia de como é que seria a Radiologia no futuro aqui. Inclusive alguns conhecimentos, como na área de ultra-som, por exemplo, aqui não era possível de se adquirir. Aqui era uma época em que só se fazia ultra-som de feto, e lá já fazia o ultra-som de fígado, de pâncreas, ainda de uma forma inicial, os primórdios dessa Radiologia abdominal, que na minha época era uma Radiologia de sombras. $\mathrm{Na}$ Radiologia convencional você não via o fígado, nem o pâncreas, via o sistema coletor dos rins, mas não se via esses órgãos, via as sombras, eram imagens indiretas, enquanto havia a tomografia de crânio que mostrava o cérebro. Então foi a transformação onde diversos órgãos do corpo humano passaram a ser vistos anatomicamente, e eles não eram vistos anatomicamente na época anterior. Foi um período de grande transformação e uma oportunidade de poder acompanhar essa transformação antes que ela viesse para o Brasil. 


\section{R.M. E o senhor acha que a Radiologia é uma das áreas que ainda tem muito a crescer?}

A Radiologia é uma área que tem um potencial de crescimento enorme. Esgotaram-se algumas fronteiras, como a anatômica. Hoje na Radiologia você vê tudo muito melhor do que no cadáver ou na cirurgia. Mas a Radiologia teve uma transformação que foi da fronteira anatômica para a fronteira funcional e hoje está partindo também para a fronteira metabólica. Atualmente estão sendo introduzidas outras fronteiras como o Molecular Image, imagens moleculares, em que se produzem substâncias que entram na célula, vinculam-se a componentes da célula e depois é possível identificá-las, ter informações a respeito do metabolismo da estrutura celular. Você pode imaginar que isso é uma fronteira infinita, quando você sai de uma fronteira anatômica para uma fronteira metabólica é como se estivesse entrando em uma estrada pista única e de repente em 200 estradas para escolher. O difícil é administrar esse progresso, essa evolução e capitalizar. Mas é por isso que nós estamos nos preparando para isso. Nós instalaremos até o começo do ano que vem o Cicloton, que é um grande aparelho que produz radio-isótopos, como a UFIG, que é utilizada no patch-CT. Mas o Cicloton produz uma grande variedade de rádio-isótopos que podem ser utilizados, por exemplo, na produção de rádio-isótopos que sejam específicos para se vincular às células de um determinado tipo de tumor, antes que o tumor apareça, antes que ele tenha $1 \mathrm{~cm}$. Ela pode detectar que existe esse tumor em uma fase microscópica e que essas partículas, que podem não ser rádio-isótopos, possam ser vinculadas à substância que vai destruir o tumor dentro da célula. Então essa fronteira envolve o diagnóstico, mas pode envolver também o tratamento. Então eu diria que a Radiologia como especialidade teria grandes fatores que vão permitir seu crescimento, principalmente nessa área funcional e metabólica, deixando a fase anatômica como uma fase já concluída no passado.

R.M. E na sua graduação o senhor participou de alguma agremiação? Atlética, Centro Acadêmico?

Eu não participei diretamente da diretoria da Atlética ou do Centro Acadêmico, mas eu freqüentava muito a Atlética, jogava tênis, um pouco de atletismo, xadrez. E eu também freqüentava o Centro Acadêmico, que era um lugar que todos freqüentavam, antes do incêndio. Era um lugar onde todo o tempo ocioso que você tinha, como intervalo de aula ou na hora do almoço, as pessoas ficavam na sala do sono, ou no restaurante. Eu ainda não vejo o CAOC ocupar completamente essa função do passado. Ficava cheio de gente, aliás, todos os alunos ficavam lá, independentemente se era da Atlética ou não. Eu não sei se é porque não se conseguiu reativar o restaurante ou ainda não foi totalmente incorporado isso. Mas o Centro Acadêmico era como se fosse uma sala de visitas. Não me lembro também dessa divisão que se tem hoje do centro acadêmico, da atlética, do departamento científico. Eu senti que as coisas ficaram divididas em certos compartimentos. Antes as pessoas freqüentavam as coisas sem essa identidade. Acho que isso aconteceu muito por causa do incêndio que houve no Centro Acadêmico, que deixou um pouco sem estrutura e teve um grupo que se vinculou mais na atlética, que ficou sendo o grupo da Atlética. Os alunos são usuários de tudo isso e as diretorias administrativas têm que cuidar para que as coisas funcionem bem. Mas eu acho que todo mundo tem que fazer esporte, tem que se socializar na escola, na área de esporte, na área de Centro Acadêmico, para quem tem vocação artística tem o Show, mas eu vejo tudo isso como uma coisa só. E me parecia que essas entidades eram mais uma coisa só, que viam um pouco do gosto de cada um. Atualmente eu sinto um pouco de uma divisão já estabelecida. Pode ser só uma impressão, mas pode ser também que depois de 30 anos a impressão que eu tinha da época também não fosse realidade, talvez as coisas também fossem divididas e a minha percepção se apagou com o tempo. Mas parecem mais divididas hoje do que era naquela época.

R.M. E como diretor da Faculdade, em que o senhor teve mais contato com as diretorias, o senhor acha interessante, acha que se aprende sendo diretor de alguma dessas agremiações?

Eu acho muito. A minha experiência como diretor da Faculdade extrapolou em todos os aspectos. Diziamme que como diretor da Faculdade eu iria ter muitos problemas com os alunos, com os docentes, mas os meus problemas foram muito poucos. O relacionamento com os alunos foi. O importante, e todos têm que ratificar isso, é que o interesse nosso, alunos e docentes, é um só, que a instituição evolua, que nós possamos fazer a instituição progredir. Então não existe uma distinção dos alunos quererem fazer a Atlética progredir, o diretor querer que a Faculdade... é uma coisa só. E nós só vamos conseguir avançar se avançarmos todos juntos e se eu ficar para trás, ficamos para trás todos juntos. Portanto, como o intuito e o objetivo de todos é a melhoria da Faculdade, sua infra-estrutura, o progresso das relações, é fácil perceber que todos querem se mover na mesma 
direção. Às vezes o que falta é apontar a direção, quer dizer, um objetivo. Mas o mais fácil é que quando todos percebem que esse objetivo é comum, todos caminham na mesma direção. A experiência que eu tive foi muito boa, eu senti que todos colaboraram e as entidades que representam os alunos colaboraram muitíssimo. Antes tinha aquele problema com o Show Medicina, que toda a vez que tinha o Show Medicina destruíam uma parte do teatro, mas o teatro já estava destruído também. Então, primeiro, o que tem que se fazer é construir um teatro novo. Depois que se tiver um teatro novo, aí se conversa com eles e se diz "Olha, o teatro está novo, todo restaurado, agora a nossa função é cuidar. Não é o diretor que tem que cuidar, todo mundo tem que cuidar". E acabou o problema. O Show Medicina nunca mais depredou o teatro, porque a gente passa a sentir que a coisa é nossa. Eu levei um choque muito grande no primeiro dia em que eu entrei como diretor da Faculdade de Medicina, porque como eu sou de área clínica, eu vou uma vez por mês à Faculdade de Medicina, não é um lugar que eu freqüento, eu vou por causa das reuniões da Congregação, eu não tenho o que fazer na Faculdade. Então na primeira vez que eu entrei como diretor, eu fiquei chocado. É uma coisa que vocês não viveram. Aquele saguão, aquela entrada nossa, só tinha compensado de madeira, era papel grudado na parede. Eu falei, puxa vida, um lugar tão bonito, parecia um mercado persa. E daí eu disse que o que tinha que ser feito era limpar aquilo. Aquele pátio todo queimado por causa do incêndio. $E$ eu vi que, ao longo que a recuperação do prédio foi sendo feita, todos foram percebendo o patrimônio físico que não são as pedras, os tijolos, o mármore, aquilo é uma história de tantas gerações. Aquilo ajudou a construir a Medicina Brasileira que hoje tem muito prestígio. Às vezes, falta um pouco entender a importância das coisas, e eu acho que ao longo dos quatro anos as pessoas foram readquirindo um pouco de amor próprio, de perceber a importância que tem a Faculdade de Medicina, o papel que exerceu a Faculdade, o Hospital. E eu sei que os alunos acompanharam essa trajetória. Acho que os alunos, com o incêndio do Centro Acadêmico, tinham perdido um pouco o ponto de apoio. Nós tivemos a oportunidade de ver essa transformação, da Faculdade de Medicina retomar o papel que nunca perdeu. Nós sempre fomos o sistema mais importante de saúde do país, mas acho que as pessoas tinham perdido um pouco a visão dessa importância. Quem está hoje na residência viveu um pouco essa transformação, viram a Faculdade de Medicina numa fase muito depressiva. Então, o relacionamento com os alunos, para mim, sempre foi muito bom. Os alunos daqui são muito bons. A Faculdade de Medicina tem um fator que é decisivo, a seleção. A seleção, porque entram aqui pessoas muito capacitadas, com uma inteligência acima da média e, portanto, já houve uma seleção natural aqui dentro. E esse patrimônio da Faculdade de Medicina nós temos que cultivar para permitir que esses alunos tornem-se médicos dentro da capacitação intelectual em que eles foram introduzidos na Faculdade de Medicina. Portanto, a infra-estrutura é importante para que se possa potencializar essa capacitação intelectual. Essa é a resposta da unidade e dos professores dessa casa. Mas eu vejo que a demanda dos alunos é fundamental para empurrar a evolução dessa instituição. Ela tem que, todos os dias, ter idéias novas e tem que se modernizar, não se pode estagnar. E nós passamos por uma fase de acomodação, de estagnação. Eu sei porque atualmente existe um movimento muito grande para poder progredir, e os alunos têm que brigar por isso. Por esse motivo, eu acho que a experiência que se tem participando desses colegiados de direção das instituições dos alunos é uma experiência de administração, em sociabilização, em discussão, em debate, que leva a ocupar espaço. Portanto, também é uma experiência muito importante que se acrescenta à formação do médico que quem puder ter, é muito bom, vai servir para a vida, e são faces que não estão no curso formado de Medicina, mas que ajudam na formação.

\section{R.M. E o que o senhor acha que foi a coisa mais importante realizada na sua gestão como diretor da Faculdade?}

Eu acho que o que é mais visível como obra do diretor é a recuperação do prédio da Faculdade, mas, para mim, o mais importante foi uma reformulação nas relações interpessoais da Faculdade, ou seja, na construção de um modelo que estabelecesse que todos são parceiros e todos têm responsabilidade no sucesso ou no fracasso do projeto. E, nesse aspecto, eu senti que tanto os alunos, os funcionários, os médicos, todos se incorporaram nesse projeto de uma modernização da nossa estrutura. Isso aconteceu fisicamente, na recuperação da Faculdade, mas aconteceu também na Fundação Faculdade de Medicina, que passou a ter uma outra perspectiva, quando eu trouxe o Fava (Prof. Dr. Flávio Fava de Moraes) para cá, aconteceu na administração do hospital, que passou a ser um hospital muito mais preocupado com resultados, qualidade de atendimento, humanização, aconteceu quando nós escolhemos um professor, porque existia um conceito aqui na Faculdade de Medicina que o professor é como um pequeno rei, um pequeno monarca, que vence um concurso e pode fazer o que quiser nas décadas 
subseqüentes. E nós mostramos que a Faculdade tem que ter princípios, tem que ter ética, e que, às vezes, se a pessoa não cumprir com os princípios, com a ética, ela pode ser excluída. Hoje o hospital é mais eficiente, mais moderno, a Faculdade é mais moderna, mas ao mesmo tempo mantém suas tradições, a sua história. Tem que olhar para frente, mas também tem que olhar para trás. E só cresce muito quem tem raízes fundas e antigas. Quem entra na Faculdade de Medicina não consegue identificar a oportunidade que está tendo, e eu sempre disse, quando tinha aquelas reuniões iniciais com os pais dos alunos, que é muito interessante você entrar em uma instituição que as pessoas entram achando a excelência do ensino de uma Faculdade de Medicina. Realmente a Faculdade de Medicina tem uma excelência de ensino, mas que, além disso, tem um Hospital Universitário com uma infra-estrutura que poucas universidades no mundo têm. $E$ tem uma infra-estrutura de convivência para o aluno, como é a Atlética, o Centro Acadêmico, o DC, o Show Medicina, que permite que o aluno vivencie aqui dentro da Faculdade de Medicina quase tudo. Não precisa ir em academia, não precisa ir buscar nenhuma atividade cultural fora, tudo acontece aqui dentro. Onde é que você tem isso em qualquer outra universidade privada? O que a Faculdade de Medicina dá para os alunos é a oportunidade de ter uma vida completa aqui dentro, pode ter a sua convivência social, a sua atividade esportiva, ter bom ensino, e ainda por cima, tudo isso sem ter que pagar a mensalidade no final do mês. Isso é uma oportunidade excepcional. Por isso os alunos têm que valorizar isso, e entender a oportunidade que estão tendo. Porque eu não vejo em contexto nacional, nenhuma escola que possa realmente dar essa oportunidade e ainda por cima depois de seis anos, depois da residência, ser um bom médico. Os alunos têm todas as oportunidades e eu acho que as entidades representativas dos alunos fazem parte desse ciclo de formação dos alunos, também são ambientes de convivência social, intelectual e esportiva que ajudam a formar o aluno, não só no aspecto técnico, mas também no aspecto social.

\section{R.M. E quanto ao projeto da reforma da Faculdade, quando que foi iniciado?}

O professor Marcelo Marcondes fez um projeto de restauro e fez um concurso público em que convidou escritórios de arquitetura e entidades a participarem no sentido de promover um restauro, uma recuperação do prédio. Eu até fiz parte, era o representante da Congregação nessa comissão que selecionou o grupo que ganhou. Na gestão do professor Irineu Tadeu Velasco teve o incêndio e daí resolveu-se que esse projeto de restauro deveria começar e foram dados os primeiros passos. Na época a FFM era dirigida pela Sandra Papaiz, que é uma empresária, e foram dados os primeiros passos para iniciar esse restauro. O restauro foi iniciado por obras no Centro Acadêmico, obras na Congregação e na construção daquele edifício lateral. As obras começaram, então, na época do professor Irineu Velasco. Quando nós assumimos, o grande problema do projeto, que era avaliado na época em quarenta e poucos milhões de reais, e que na verdade acabaram se tornando mais de setenta, por causa do escopo do projeto, era que os recursos eram muito poucos. O Banespa tinha dado um dinheiro porque ia ficar com a agência aqui nos fundos, o Fleury tinha patrocinado uma reforma fixa do Centro Acadêmico. Os recursos para o restauro eram pequenos, e parecia realmente um desafio muito grande ou um projeto que iria se arrastar por muitos anos, sabe aquela obra que leva uns 10 , 15, 20 anos? Então, a grande dificuldade foi como equacionar a entrada de recursos que permitisse que durante os quatro anos pudessemos resolver a questão do restauro. Inicialmente parecia uma coisa impossível porque era muito dinheiro, muita obra e poucos recursos. Daí nós fizemos uma comissão de professores e pessoas da sociedade, uma comissão de restauro e nós conseguimos, aos poucos, com doações da área privada, realizar o projeto. E a comissão ficava motivada porque a cada ano o projeto tentava inaugurar uma coisa para que as pessoas sentissem que a coisa estava andando. Então o que parecia difícil se tornou possível e realizável graças à mobilização da comunidade aqui dentro, em particular dessa comissão de restauro, e também do apoio da sociedade. Claro também que a figura do diretor é uma figura importante porque o contato inicial poderia ser feito por outras pessoas, mas na hora do pedido formal só o diretor poderia estar lá. Ao longo desses anos pedindo recursos eu só recebi não de uma pessoa só, todos os outros colaboraram mais ou menos, mas depois todos colaboraram. Todos os empresários, todos colaboraram e, no final, eu vejo até o Banespa que tinha se disposto a dar um montante, deu três vezes mais. Então é realmente um projeto que mostra que com empenho, mobilizando um grupo, gente comprometida, que nada é impossível, tudo pode ser feito. Agora, precisa de tempo, precisa que as pessoas percebam a importância do projeto. Mas é muito fácil vender um projeto que envolva a Faculdade de Medicina da USP e o HC. Nós tivéssemos um produto para ser vendido para a sociedade, como uma colaboração para um projeto histórico, cultural e social, é um produto fácil de ser vendido. Mas eu acho que a lição que isso mostra é que nada é impossível. Temos que ter vontade e 
garra para poder levar um projeto adiante, porque, realmente, a realização desse projeto, que parecia difícil, acabou se concretizando. Foi um projeto muito importante para a auto-estima da instituição, porque, no fundo, ao longo dessa época houve muitas obras marcantes, como a reforma do Instituto de Psiquiatria, o ICHC, a conclusão do Instituto Dr. Arnaldo, que foi um pedido meu ao Governador do Estado, quer dizer, muita coisa mudou, mas a Faculdade é sempre a jóia da coroa, por isso era muito importante recuperar aquele prédio. E o papel da Fundação foi fundamental, a Fundação se engajou muito nisso. Grande parte dos recursos acabou sendo mobilizada pela própria instituição. É aquela história que deu certo com muita luta e muito esforço de todos, e os alunos também participaram desse projeto. Foi muito interessante quando nós promovemos o primeiro encontro de Antigos Alunos aqui. Nós procuramos o endereço de todos os antigos alunos possíveis, convidamos todos para irem para a Faculdade de Medicina, e muitos não vinham aqui há 20 anos, 30 anos, 40 anos. Acho que isso foi muito estimulante para que as pessoas voltassem para a Faculdade. Quem passa aqui seis anos, oito, nove anos no mínimo, na melhor das hipóteses, não rompe. Todos nós passamos uma época muito importante aqui. Então, por mais que você não tenha ficado na Instituição, você têm boas lembranças dessa fase. Acho que todos apreciaram muito poder vir, voltar e se reencontrar. O encontro de gerações foi um resgate interessante nessa história.

R.M. E depois desses 95 anos da Faculdade, quais o senhor acha que são as perspectivas para o futuro, o que vai mudar na Graduação, diretamente?

Eu acho que as perspectivas para a Faculdade são boas. O Hospital Escola, não só o HC, mas a expansão da Faculdade, no atendimento primário, secundário, permite hoje uma visão integrada da saúde para o aluno. A nossa infra-estrutura é boa, tanto aqui, como no $\mathrm{HU}$, nas reformas que estão sendo introduzidas no atendimento primário. $O$ ensino hoje tem uma infraestrutura boa, a pesquisa está crescendo bastante. Então, vejo boas oportunidades, tanto na assistência, pela boa infra-estrutura do hospital, quanto na pesquisa que, em números, é crescente, e os laboratórios estão se modernizando, quanto no ensino que hoje tem uma infra-estrutura que permite o ensino mais moderno. Portanto, eu vejo a oportunidade nas três áreas. Acho que o $\mathrm{HC}$ vai cumprir melhor sua missão, o ensino vai continuar sendo de qualidade, com oportunidades melhores, e a pesquisa está evoluindo. Acho que as oportunidades vão ser boas para a Instituição, já para o médico que vai se graduar aqui na Faculdade de Medicina, a perspectiva no mercado de trabalho está piorando. Inúmeras escolas de má qualidade estão sendo abertas. A situação do médico é que está se deteriorando. Acho que o mercado de trabalho vai piorar, é uma profissão que cresce, enquanto as perspectivas profissionais decrescem. Não sei se em algum momento a carreira médica vai piorar a ponto de acabar prejudicando a qualidade das pessoas que entram aqui. Mas eu vejo que o Direito já passou por isso e a São Francisco continua sendo procurada, continua sendo, de certa forma, a grande escola de Direito que existe. Atualmente, o maior problema que nós temos não são os inimigos internos, o problema é da carreira médica e o futuro do médico. Essa é a grande angústia que tem que nos preocupar, a situação do médico, da formação do médico, do número de médicos que vai ter por aí, na qualidade da Medicina e no mercado de trabalho. 